\title{
Recent Advances in the Synthesis and Characterization of Nanoparticles: A Green Adeptness for Photocatalytic and Antibacterial Activity
}

\author{
Thambiraj Arthi Feiona, G. Sabeena, Muthiah Sakthi Bagavathy, E. Pushpalaksmi, J. Jenson Samraj \\ and G. Annadurai $\uparrow$ \\ Division of Nanoscience, Sri Paramakalyani Centre for Excellence in Environmental Sciences, Manonmaniam \\ Sundaranar University, Alwarkurichi-627 412, India \\ $\dagger$ Corresponding author: G. Annadurai; gannadurai@ msuniv.ac.in
}

\author{
Nat. Env. \& Poll. Tech. \\ Website: www.neptjournal.com \\ Received: 26-05-2020 \\ Revised: $18-07-2020$ \\ Accepted: 25-07-2020 \\ Key Words: \\ Green synthesis \\ Lantana camara Linn. \\ $\mathrm{NiO}$ nanoparticles \\ Photocatalytic activity \\ Antibacterial activity
}

\begin{abstract}
The green synthesis of metal oxide nanoparticles is an eco-friendly, rapid, and cost-effective development of novel technologies. The catalyst of nickel oxide ( $\mathrm{NiO}$ ) nanoparticles has been synthesized by the green route's method using Lantana camara Linn and nickel chloride. It was found that plant-mediated synthesis of nickel oxide nanoparticles can greatly enhance the antibacterial and photocatalytic activity at very low concentrations. The synthesized plant-mediated $\mathrm{NiO}$ nanoparticle was characterized by the structural and optical properties, morphology, and composition of NiO nanoparticles (NPs) with the help of various techniques such as Ultra Violet (UV) spectroscopy, Fourier Transform Infrared Spectroscopy (FTIR), Scanning Electron Microscopy (SEM), X-ray Diffraction (XRD), Particle Size Analyzer (PSA), Fluorescence Spectroscopy (FL) and the photocatalytic activity studies were investigated. The antimicrobial activity was carried out against Gram-positive and Gram-negative bacteria and NiO NPs showed inhibitory activity in both strains of bacteria with excellent selectivity against Gram-positive bacteria.
\end{abstract}

\section{INTRODUCTION}

Nanoparticles (NPs) are a cluster of atoms having at least one dimension in the size range of 1-100 $\mathrm{nm}$. Owing to their unique optical, magnetic, catalytic, and electrical properties, they have potential applications in various fields. The physicochemical properties of NPs are different as compared to those of their bulk counterparts because the surface area to volume ratio increases and quantum effects become dominant as the size decreases. The increase in surface area to volume ratio alters the mechanical, catalytic, and thermal properties of the material (Muhammad et al. 2016). There are several methods for creating nanoparticles, including attrition, pyrolysis, hydrothermal synthesis, and green synthesis. The most common methods are solvothermal, co-precipitation method, bottom-up and top-down synthesis, sol-gel synthesis method, green synthesis, and chemical synthesis method (Joerger et al. 2011). Green synthesis is a cost-effective system and eco-friendly system (Morton et al. 2016). Green synthesis is used in various for different applications and it is used in day-to-day life. Green synthesis of nanoparticles is a cost-effective and eco-friendly system with the added advantage of stabilizing the formed NPs as plant secondary metabolites besides acts as synthetic agents as well as a capping agent. Plant-mediated synthesis of nanoparticles is a green chemistry approach that connects nanotechnology with plants. Plants are nature's chemical factories (Mariam et al. 2014). As the green synthesized nanoparticles are smaller in their small size, they can penetrate small capillaries and are taken up by the cells, which allow efficient drug accumulation at the target (Laokul et al. 2009). Moreover, NPs synthesized by using green chemistry have no or low cytotoxicity as compared to other chemically synthesized NPs which makes them an efficient carrier of drugs for in vivo drug delivery applications. Lantana camara Linn $(L$. camara) is a popular ornamental and garden plant that grows up to 2-4 meters in height, with several flower colours such as yellow, red, pink, and white. It also grows naturally at roadsides or riversides up to the elevation of 2,000 meters in tropical and subtropical temperature regions. The leaves of the plant are used in the treatment of tumours, tetanus, rheumatism, malaria, etc., and it is used in the antiseptic and carminative properties have also been reported (Ganjewala et al. 2009, Raju 2000 \& Ghisalberti 2000). In the past few decades, metal oxide nanoparticles have been gaining momentum among researchers. One of the most extensively used transition metal oxides is Nickel oxide $(\mathrm{NiO})$ which has a wide bandgap and various applications. They encompass catalysis, lithium-ion batteries, smart windows, antiferromagnetic film, dye-sensitized photocathodes, 
photocatalysis, antimicrobial activity, thermal conductivity, and field emission studies. Different kinds of researches were undertaken in NiO NPs prepared by cost-effective and eco-friendly methods that have been used to evaluate their antimicrobial activity and for photocatalytic degradation of rhodamine B. The antibacterial activity of such nanoparticles depends on their stability, size, and concentration added to the bacterial growth medium since this provides greater retention time for interaction of bacterium nanoparticles (Alamelu et al. 2015 \& Azam et al. 2012).

In this work, for the first time, we have synthesized nickel oxide nanoparticles using Arabic gum, and nickel chloride as the nickel source, and water as solvent by sol-gel process, without any surfactant and reducing agent, as a cheap and eco-friendly approach to nature. This method has many advantages such as nontoxic, versatile, low cost, and could be used to synthesize other metal oxides. The influence of calcination time on structure, morphology, composition, and photoluminescence property of $\mathrm{NiO}$ nanoparticles was investigated in detail and antimicrobial activity of $\mathrm{NiO}$ nanoparticles is tested against bacterial species using the disc diffusion method.

\section{MATERIALS AND METHODS}

The Lantana camara leaves were collected from the Tenkasi area which is near to the Western Ghats region. Nickel chloride $\left(\mathrm{NiCl}_{2} \cdot 6 \cdot \mathrm{H}_{2} \mathrm{O}\right)$ was purchased from Daijung (Darmstadt, Korea) and used without further purification.

\section{Synthesis of Leaf Extract}

The Lantana camara leaves were dried for one day under the shadow and are thoroughly washed with distilled water to remove dust particles and sun-dried to remove moisture content and these leaves are cut into small pieces. Then the leaves are boiled in distilled water in a flask for 6 hours and placed in a water bath at a constant temperature for three hours at $400^{\circ} \mathrm{C}$. The solution was filtered and finally, 100 $\mathrm{mL}$ of leaf extract was obtained and the extract was filtered using Whatman filter paper and finally, the leaf extract was obtained.

\section{Synthesis of Nickel Oxide Nanoparticles}

The $\mathrm{NiCl}_{2}(0.5 \mathrm{M})$ was prepared individually and mixed with $10 \mathrm{~mL}$ of plant extract and kept at room temperature. The colour of the solution was changed from light green to brown colour indicating the formation of $\mathrm{NiO}$ nanoparticles and the absorbance of nickel oxide nanoparticles in the solution was monitored at different time intervals using UV-visible spectroscopy.

\section{Photocatalytic Activity}

The photocatalytic activity of NiO NPs was evaluated on the degradation of methylene blue (MB) (Merck, India) in an aqueous solution under UV light $\left(125 \mathrm{~W} / \mathrm{m}^{2}\right.$, Osram) illumination. A known weight of the catalyst, $0.01 \mathrm{~g}$ was added to a known volume of $0.2 \mathrm{~L}$ dye that resulted in a suspension. The suspension was stirred for uniform exposure of the catalyst to light. The distance between the lamp and the base of the beaker under UV illumination was $13 \mathrm{~cm}$. Each experiment was conducted every $120 \mathrm{~min}$ with a $10 \mathrm{~mL}$ sample of a liquid drawn every $15 \mathrm{~min}$. The degradation of the dye was monitored after the removal of photocatalyst by centrifugation at $2000 \mathrm{rpm}$ for $30 \mathrm{~min}$. The decreased absorbance was measured at regular intervals of time from 0 to $120 \mathrm{~min}$ by using the Shimadzu UV1650 PC spectrometer.

\section{RESULTS AND DISCUSSION}

The synthesized $\mathrm{NiO}$ nanoparticles are subjected to various characterization studies for their structural, optical, and magnetic properties such as powder XRD, UV-visible spectrometer, FTIR spectrometer, particle size analyser, fluorescence spectroscopy, and SEM analysis. The results obtained are discussed below.

\section{X-ray Diffraction (XRD)}

The peaks seem to be appreciably broad that indicates the crystallites of the hydroxide can be in the nanosized range. The structural information and crystallinity of NiO NPs were prepared using Lantana camara plant extract by green synthesis method and are further studied by the XRD pattern as shown in Fig. 1. The sharp peaks of NiO NPs are highly crystalline. The observed peaks appreciably broad indicating that the synthesized Nickel hydroxide nanoparticles are crystalline with the hexagonal phase. The diffraction peaks of NiO NPs at $2 \theta=37.21^{\circ}, 43.29^{\circ}, 62.88^{\circ}$ associated with the crystal planes (111), (200), (222) were observed (Mallikarjuna et al. 2017). The obtained result was well-matched with JCPDS No. 1313-99-1. The obtained XRD pattern reveals the formation of NiO NPs and showed no other peaks present in the XRD data. It is observed that peaks are sharp with high intensity for higher calcination time which means that bigger particle size may be generated by increasing the calcination time (Rajesh et al. 2010 \& Shanaj et al. 2016). However, it can be observed that, by increasing the calcination temperature up to $400^{\circ} \mathrm{C}$, the peaks have been appreciably sharpened which indicates that the growth in the crystallite sizes of $\mathrm{NiO}$ has occurred.

It was confirmed that the purity of the $\mathrm{NiO}$ phase. The crystalline size of NiO NPs was estimated using the Debye Scherrer formula. 


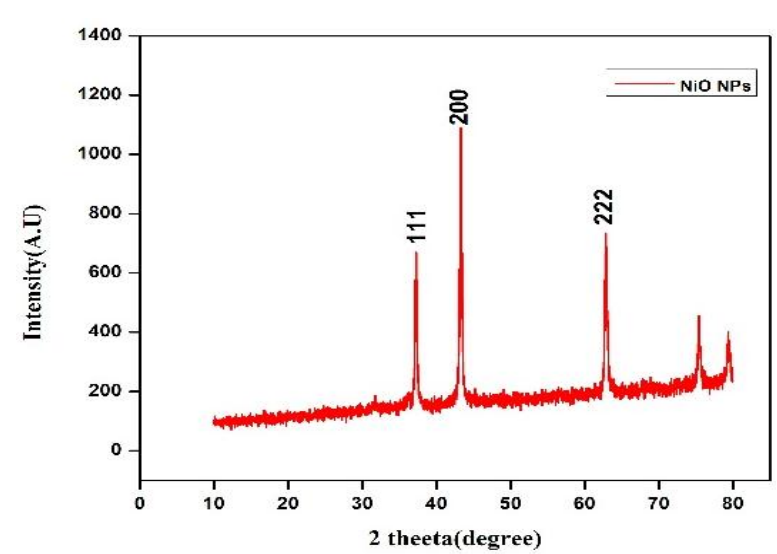

Fig. 1: XRD image of NiO Nanoparticle.

$$
\mathrm{D}=0.89 \lambda / \beta \cos \theta
$$

Where $\mathrm{D}$ is the average crystal size $\lambda$ is a wavelength of the $\mathrm{X}$-ray radiation and $\beta$ is the full-width half maximum. The calculated average of crystalline size was formed to be $21 \mathrm{~nm}$. The reduced crystalline size may be due to the plant extract that can act as the capping agent and reducing agent with the NiO NPs. Moreover, it will have a remarkable impact on biological activity.

\section{Fourier Transform Infra-Red Spectroscopy (FT-IR)}

Fig. 2 shows the FT-IR spectra of the prepared sample of $\mathrm{Ni}(\mathrm{OH})_{2}$ and $\mathrm{NiO}$ nanoparticles after calcination at different periods. In Fig. 2, a sharp peak at $3637 \mathrm{~cm}^{-1}$ is the characteristic of $\mathrm{Ni}(\mathrm{OH})_{2}$ (Rajesh et al. 2010, Shanaj et al. 2016, Motlagh 2011 \& Abolanle 2011). The broad absorption band centred at $3403 \mathrm{~cm}^{-1}$ is assigned to $\mathrm{O}-\mathrm{H}$ stretching vibrations and the weak band at $1633 \mathrm{~cm}^{-1}$ is attributed to $\mathrm{H}-\mathrm{O}-\mathrm{H}$ bending vibration because of absorption of water molecules from the air as the sample was synthesized. Fig. 2 shows the FTIR spectra of prepared NiO NPs. The FTIR bands due to metal-oxygen occur in the region of $400-4000 \mathrm{~cm}^{-1}$. The FTIR shows the peaks at $3480 \mathrm{~cm}^{-1}, 1650 \mathrm{~cm}^{-1}, 473 \mathrm{~cm}^{-1}$. The intense and wide peak centred at $3480 \mathrm{~cm}^{-1}$ assigned to $\mathrm{O}-\mathrm{H}$ stretching and the peak at $1650 \mathrm{~cm}^{-1}$ corresponds to the $\mathrm{H}-\mathrm{O}-\mathrm{H}$ bending mode. The band at around $473 \mathrm{~cm}^{-1}$ is attributed to Ni-O bending vibration. These results agree with other researches (Wang et al. 2009). The dislocation density, which is a crystallographic defect within a crystal structure affects the properties of materials. The bands at $3368 \mathrm{~cm}^{-1}$ are assigned to $\mathrm{O}-\mathrm{H}$ stretching vibration and $1585 \mathrm{~cm}^{-1}$ are due to $\mathrm{O}-\mathrm{H}-\mathrm{O}$ bending vibration mode because the calcined powder tends to absorb water. The bands due to carbonate groups and C-O stretching bonds are observed at $1424 \mathrm{~cm}^{-}$ ${ }^{1}, 872 \mathrm{~cm}^{-1}$, and $1036 \mathrm{~cm}^{-1}$ respectively. The appearance of new bands was observed at $557 \mathrm{~cm}^{-1}, 405 \mathrm{~cm}^{-1}$ which are

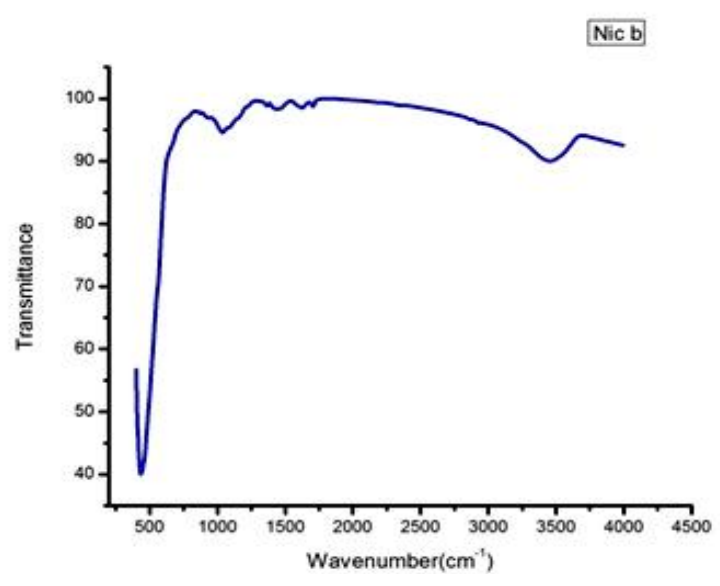

Fig. 2: FT-IR functional group peaks of NiO Nanoparticle.

assigned to Ni-O stretching vibration mode (Rajesh 2010, Shanaj 2016 \& Motlagh 2011). The broadness of the band indicates the nanocrystalline nature of the samples.

\section{Scanning Electron Microscopy}

The surface morphological features of synthesized nanoparticles were studied by scanning electron microscope. The images were recorded with magnification of 500 and 10000 as shown in Fig. 3. The results indicate that $\mathrm{NiO}$ nanoparticles are hexagonal. We can observe that the particles are highly agglomerated. (Mallikarjuna et al. 2019). Further, the particles are aggregated with irregular particle morphology having a diameter of $1 \mu \mathrm{m}$ and they are essentially a cluster of nanoparticles.

The presence of some larger nanoparticles may be attributed to the fact that $\mathrm{NiO}$ nanoparticles tend to agglomerate due to their high surface energy and high surface tension of the ultrafine nanoparticles (Muhammad et al. 2016)

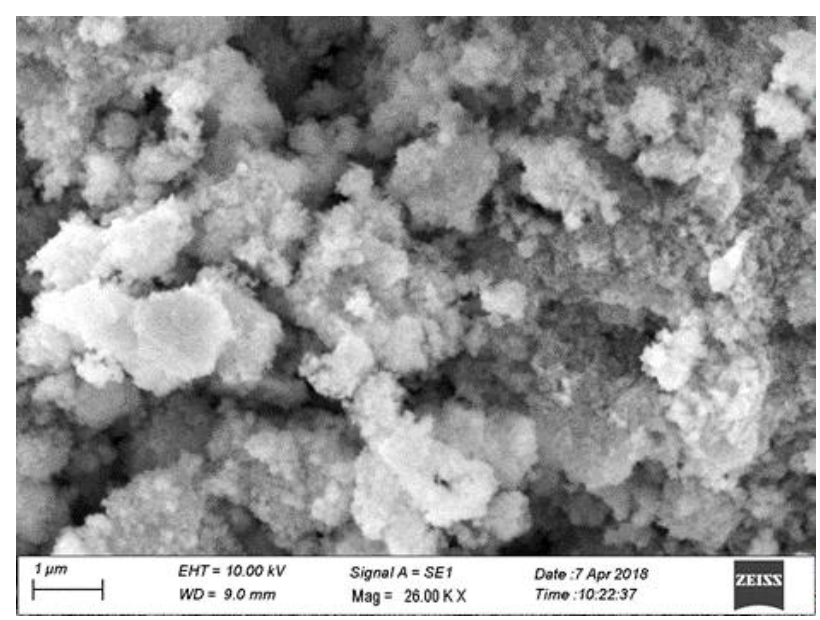

Fig. 3: SEM image of synthesized NiO nanoparticles. 


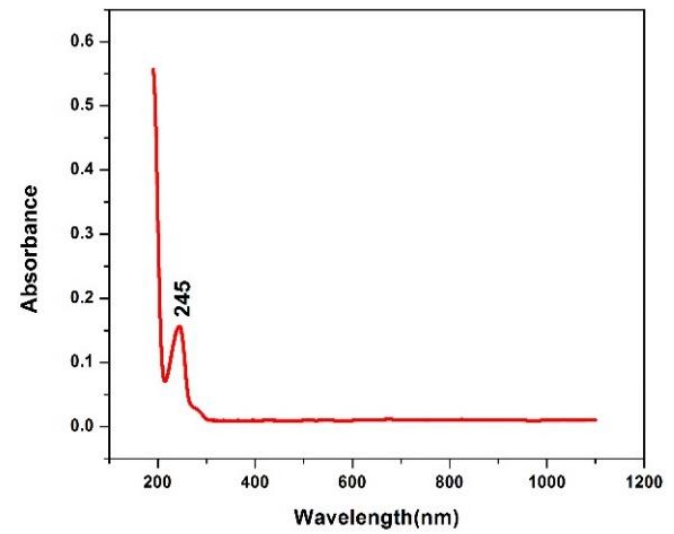

Fig. 4: UV-visible spectroscopy synthesized peak for $\mathrm{NiO}$ nanoparticles.

\section{Ultra Violet Visible Spectroscopy}

The UV spectral studies are taken for the $\mathrm{NiO}$ nanoparticles in regions ranging between 200 and $1200 \mathrm{~nm}$. The absorption spectra of plant extract mediated synthesis of $\mathrm{NiO}$ nanoparticles in terms of wavelength are shown in Fig. 4.

The UV spectra show that the absorption peak wavelength for plant extract mediated synthesis of $\mathrm{NiO}$ nanoparticles is around $245 \mathrm{~nm}$. From the absorption spectra, it is confirmed that the peak is due to the Nickel oxide nanoparticle present here. The plots of variation of wavelength versus absorption for the plant extract mediated synthesis $\mathrm{NiO}$ nanoparticles are presented (Mallikarjuna et al. 2017 \& Haque et al. 2009). The UV-visible absorption spectrum of the $\mathrm{NiO}$ particles obtained at plant extract mediated synthesis. A slight shift towards a higher wavenumber is seen for the absorption edges by increasing the processing temperature. This shift indicates a decrease in the bandgap, which can be attributed to an increase in particle size. The increasing trends of the bandgap energy upon the decreasing particle size is likely due to the defects or vacancies present in the intergranular regions generating new energy levels to reduce the bandgap energy.

\section{Fluorescence Spectroscopy}

The fluorescence spectra of Nickel oxide nanoparticles, which are essential in comparing the fluorescence properties. Fig. 5 shows the fluorescence spectrum of Nickel oxide nanoparticles where the peaks are observed at $645 \mathrm{~nm}$, where $645 \mathrm{~nm}$ luminescence peak is based on the near-and-edge emission of Nickel oxide nanoparticles (Linsebigler et al. 1995).

The fluorescence of the plant-mediated synthesis of Nickel oxide nanoparticle exhibited emission peaks at 645 $\mathrm{nm}$ as shown in Fig. 5. The fluorescence spectra were not

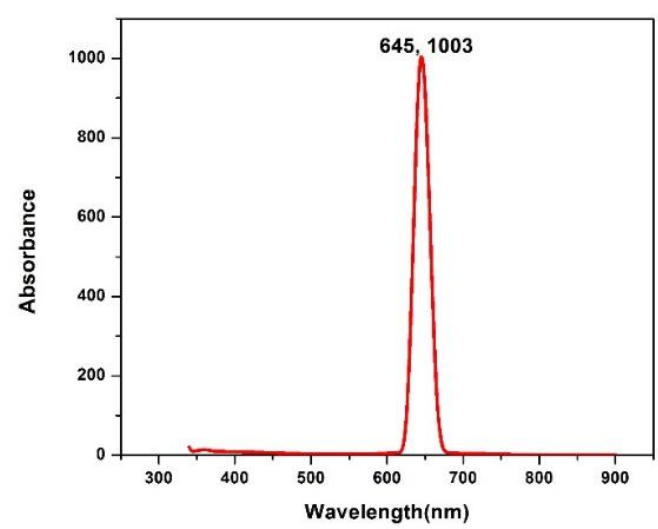

Fig. 5: FL peaks of Nickel oxide nanoparticles.

quenched and showed good fluorescence (Helan et al. 2016 $\&$ Dutta et al. 2011). The emission peaks were red-shifted on the change of the excitation from $645 \mathrm{~nm}$ and the intensity of fluorescing spectra was reduced by increasing the excitation wavelength (Haque et al. 2009).

\section{Particle Size Analyzer}

The Particle Size Distribution (PSA) of plant-mediated synthesized Nickel oxide nanoparticles was analysed by PSA as shown in Fig. 6. PSA result showed the particle size distribution of plant-mediated synthesized by Nickel oxide nanoparticles at $10-50 \mathrm{~nm}$. This size proved that the synthesized Nickel oxide nanoparticle using Lantana camara leaf extract was in nanoparticle form. Fig. 6 shows the PSA graph of plant-mediated synthesis of nickel oxide nanoparticles.

The synthesized plant-mediated Nickel oxide nanoparticle exhibits a mean particle size of $21 \mathrm{~nm}$ under dynamic light scattering. The crystalline size was calculated from PSA is further counter-verified by Powder X-Ray Diffraction (PXRD).

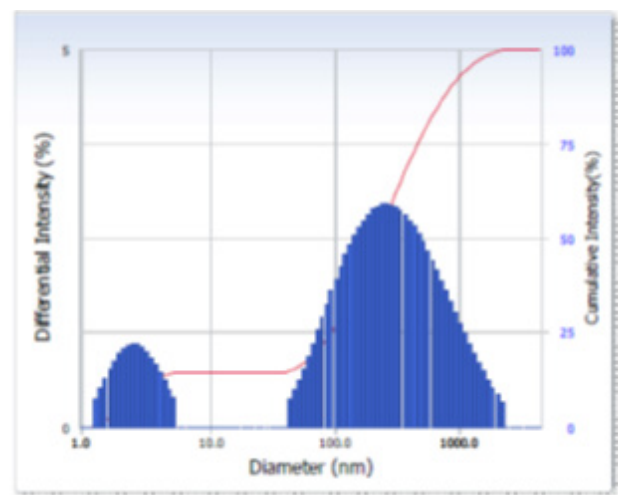

Fig. 6: DLS peaks of Nickel oxide nanoparticles. 


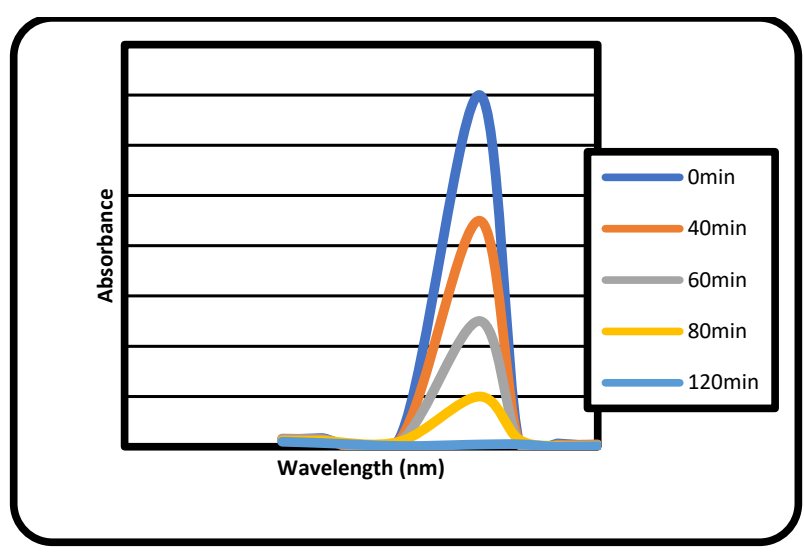

Fig.7: Photocatalytic image of $\mathrm{NiO}$ nanoparticles.

\section{Photocatalytic Activity}

Fig. 7 shows the photocatalytic degradation of methylene blue dye molecule using plant-mediated synthesis. Nickel oxide nanoparticles are performed at room temperature under UV light at a wavelength of $664 \mathrm{~nm}$. The least peak was noticed at $650 \mathrm{~nm}$ indicates the decreased level of methylene blue (MB) dye molecule with increasing UV exposure time that denotes the degradation of dye molecule at UV-irradiation.

This shows $85 \%$ of the degradation rate of dye molecule using biologically synthesized nickel oxide nanoparticles within $120 \mathrm{~min}$ is due to excitation of semiconductor by UV-light to produce free radicals in the degradation of dye in which the excited electrons move from the valence band to the conduction band and generates high energy electron-hole pairs which transfer to adsorbed species on semiconductor results heterogeneous photocatalysis (Wu et al. 2015 \& Linsebigler et al. 1995). The photocatalytic activity was done within $2 \mathrm{hrs}$ and the methylene blue dye $(0.2 \mathrm{~L})$ was degraded successfully. Moreover, we have observed NiO NPs as an efficient photocatalytic adaptive nanoparticle.

\section{Antibacterial Studies}

The antibacterial activities of plant-mediated synthesis of nickel oxide nanoparticles are generally known to be a function of the surface area which is in contact with the microorganisms. Reactions take place at the surface of a plant-mediated synthesis of nickel oxide nanoparticles (Dola et al. 2017 \& Miessya et al. 2019). The antibacterial activity of NiO NPs can generate oxidative stress to damage the structure, protein, and bacterial cells. Further, it prevents the formation of biofilms and assists in wound healing (Srihasam et al. 2020). Hence, the smaller size and the higher surface to volume ratio, i.e. larger surface area, enhanced interaction with the microbes is seen. Fig. 8 shows the antibacterial activity of plant-mediated synthesis of Nickel oxide nanoparticle from the microorganism such as Escherichia coli, Bacillus subtilis, and Enterobacter.

The activity was found to be highest in the case of Gram-negative bacteria and Gram-positive bacteria. Plant-mediated synthesis of Nickel oxide nanoparticle samples showed activity for Gram-positive and Gram-negative bacteria such as Escherichia coli, Bacillus subtilis, and Enterobacter. The concentration of Plant-mediated synthesis of Nickel oxide nanoparticles such as $20 \mu \mathrm{L}$, $40 \mu \mathrm{L}, 60 \mu \mathrm{L}, 80 \mu \mathrm{L}$ and then the zone of inhibition of the nickel oxide nanoparticle against Gram-positive and Gram-negative bacteria. The mechanism depends not only on the concentration of NiO NPs; it also depends on the sensitivity of bacterial species. The increased antibacterial effect may be due to reactive radicals $\mathrm{Ni}^{2+}$ ions (Rajesh et al. 2010 \& Krishnamoorthy et al. 2012), released continuously in the solution (Wang et al. 2007), may be attached to the negatively charged bacterial cell wall due to electrostatic force. The strong adhesion of $\mathrm{Ni}^{2+}$ ions to the bacterial cells causes the distraction of cell membranes (Morones et al. 2005. Wang et al. 2007, Makhluf et al. 2005, Sawai et al. 2003 \& Jadhav et al. 2011), and hence antimicrobial efficacy at higher NPs concentration (Rajesh et al. 2010 $\&$ Fu et al. 2005). The antibacterial results also revealed that Gram-positive bacteria are more susceptible to $\mathrm{NiO}$ nanoparticles as compared to Gram-negative bacteria due to the difference in the cell wall structure. The cell wall of Gram-positive bacteria is made of a thick layer of
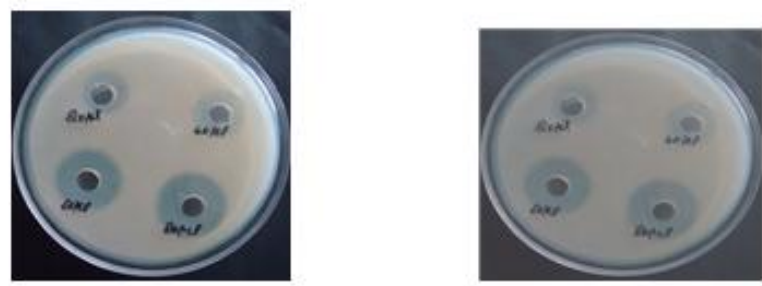

Escherichia Coli Bacillus Subtilus

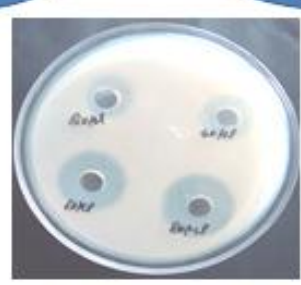

Enterobacter

Fig. 8: Antibacterial activity of the plant-mediated synthesis of $\mathrm{NiO}$ nanoparticles. 
peptidoglycan, which is attached to teichoic acids that are unique to Gram-positive bacteria and can be damaged more easily (Rajesh et al. 2010 \& Motlagh et al. 2011). But in Gram-negative bacteria, the cell wall contains a thin peptidoglycan layer and an outer membrane, constructed from tightly packed lipopolysaccharide (LPS) molecules (Rajesh et al. 2010), which is selectively permeable and regulates the transport through the plasma membrane. This renders Gram-negative bacteria less susceptible to NiO NPs (Mani et al. 2013, Tortora et al. 2016).

\section{CONCLUSION}

In conclusion, this paper provides an overview of the plant-mediated synthesis of nickel oxide nanoparticles by using plant extract. Although all these green protocols for $\mathrm{NiO}$ nanoparticle synthesis have their advantages and limitations use of plant extract as a reductant is more beneficial as compared to microbial extract because of the rapid rate of production of nanoparticles with a former green reductant. Synthesis of $\mathrm{NiO}$ nanoparticles was carried out by the green synthesis method using Lantana camara leaf extract. XRD and FT-IR confirm the formation of pure and crystalline $\mathrm{NiO}$ nanoparticles and various functional groups present in these particles to synthesize with high purity and crystallinity, reduced particle size, and more surface defects, which are the advantageous factors to be used for various environmental and applications. The UV-visible spectra showed that the wavelength is around $245 \mathrm{~nm}$. FTIR studies were carried out for the functional group from the crystalline sample and the vibrational bands are assigned. From SEM images, it is observed that the nanoparticles are arranged as regular beads in shape. The fluorescence spectrum of nickel oxide nanoparticles where the peaks are observed at $645 \mathrm{~nm}$, where $645 \mathrm{~nm}$ luminescence peak is based on the near-band-edge emission of nickel oxide nanoparticles. It is also concluded that the antimicrobial property of $\mathrm{NiO}$ nanoparticles increased with an increase in surface area to volume ratio due to a decrease in particle size. Hence, smaller-sized $\mathrm{NiO}$ nanoparticles can be used as an antimicrobial agent more effectively. Based on the results, it is concluded that particle size and optical properties are controlled by calculations time. Hence, $\mathrm{NiO}$ nanoparticles can also be used in optoelectronic devices. The morphology and chemical composition were elucidated by SEM. The photocatalytic degradation of methylene blue dye molecule using the plant-mediated was successfully synthesized. The least peak is noticed at $650 \mathrm{~nm}$ indicates the decreased level of MB dye molecule with the increasing UV exposure time denotes the degradation of dye molecule at UV-irradiation.

\section{ACKNOWLEDGEMENT}

Myself, T. Arthi Feiona (Register No: 17211232272011) acknowledge the Research Centre Sri Paramakalyani Centre for Excellence in Environmental Science, Manonmaniam Sundaranar University, Alwarkurichi, for providing the support for this research work.

\section{REFERENCES}

Abolanle, S., John Oyekunle, A., Oluwatobi, S. and Abiodun J. O. 2011. Comparative catalytic properties of $\mathrm{Ni}(\mathrm{OH})_{2}$ and $\mathrm{NiO}$ nanoparticles towards the degradation of nitrite $\left(\mathrm{NO}_{2}^{-}\right)$and nitric oxide (NO). Int. J. Electrochem. Sci., 9: 3008-3021.

Alamelu, K., Ramasami, M., Reddy, V., Geetha, R. and Balakrishna, R. 2015. Combustion synthesis and characterization of $\mathrm{NiO}$ nanoparticles. Materials Science in Semiconductor Processing, 40: 194-202.

Azam, A., Ahmed, A.S., Oves, M., Khan, M.S. and Memic, A. 2012. Sizedependent antimicrobial properties of $\mathrm{CuO}$ nanoparticles against Grampositive and negative bacterial strains. Int. J. Nanomed., 7: 3527-3535.

Dola, S. T., Vijaya Kumar, P.S., Subba Rao, R., Ravikumar, V.S.S.N. and Gopala Krishna, A. 2017. Green synthesis and characterization of Ag nanoparticles from Mangifera indica leaves for dental restoration and antibacterial applications. J. Bio and Tribo-Corrosion, 6: 57-66.

Dutta, M., Jana, S. and Basak, D. 2011. Quenching of photoluminescence in $\mathrm{ZnO}$ QDs decorating multiwalled carbon nanotubes. Chem. Phys. Chem., 11(8): 1774-1779.

Fu, G. Vary, P.S. and Lin, C.T. 2005. Anatase $\mathrm{TiO}_{2}$ nanocomposites for antimicrobial coatings. J. Phys Chem, B., 12: 8889-8898.

Ganjewala, D., Sam, S. and Khan, K.H. 2009. Biochemical compositions and antibacterial activities of Lantana camara plants with yellow, lavender, red, and white flowers. Eurasian J. Bio. Sci., 3: 69-77.

Ghisalberti, E.L. 2000. Lantana camara L. (Verbenaceae). Fitoterapia, Fitoterapia, 71(5): 467-486.

Haque, F.Z., Singh, N., Pandey, P. and Parra, M.R. 2009. Study of zinc oxide nano/micro rods grown on ITO and glass substrates. Optik-Int. J. Light Electron. Opt., 124(20): 4167-4171.

Helan, V., Joseph Prince, J., Al-Dhabi, N.A., Valan Arasu, M., Ayeshamariam, A., Madhumitha, G., Roopan, S.M. and Jayachandran, M. 2016. Neem leaves mediated preparation of $\mathrm{NiO}$ nanoparticles and their magnetization, coercively, and antibacterial analysis. Results Phys., 6: 712-718.

Jadhav, S., Gaikwad, S., Nimse, M., Rajbhoj, A. and Clust, J. 2011. Copper oxide nanoparticles: synthesis, characterization, and their antibacterial activity. J. Cluster Sci., 22: 121-129.

Joerger, R., Klaus, T. and Granqvist, C.G. 2011. Biologically produced Ag-C composite for optically functional thin-film coating. Adv. Mate., 12: 407-409.

Krishnamoorthy, K., Moon, J.Y., Hyun, H.B., Cho, S.K. and Kim, S.J. 2012. Mechanistic investigation on the toxicity of $\mathrm{MgO}$ nanoparticles toward cancer cells. J. Materials Chemistry, 22: 24610- 24617.

Laokul, P., Amornkitbamrung, V., Seraphin, S. and Maensiri, A. 2009. Growth of p-type $\mathrm{ZnO}$ thin film on n-type silicon substrate and its application. Curr. Appl. Phys., 4: 101-111.

Linsebigler, A.L., Lu, G.Q. and J.T. 1995. Photocatalysis on TiO2 surfaces: principles, mechanisms, and selected results. Chem. Rev., 95: 735-758.

Makhluf, S., Dror, R., Nitzan, Y., Abramovich, Y. and Jelinek, R. 2005. Microwave assays synthesis of nanocrystalline $\mathrm{MgO}$ and its use as a bacterioside. Adv. Funct. Mater., 15: 1708-1715.

Mallikarjuna, K., Kotesh Kumar, M., Subba Reddy, B.V. and Kim, H. 2019. Hydrogen production from water splitting: Fabrication of $\mathrm{ZnO}$ nanorod 
decorated $\mathrm{Cu}$ NW heterogeneous hybrid structures for photocatalytic applications. J. Clust. Sci., 30: 449-457.

Mallikarjuna, K., Raju, B.D.P. and Kim, H.S. 2017. Sustainable fabrication of palladium nanoparticles using Stevia rebaudiana tea and its catalytic activity. J. Nanosci. Nanotechno., 217: 4251-4256.

Mani, R. K., Padmanathanb, N., Reji, P., Balamurugand, S. and Kanakam, C.C. 2013. Size determination of nickel oxide nanoparticles by electrochemical reduction method and its antibacterial activity. Appl. Surface Sci., 282: 656-661.

Mariam, A.A., Kashif, M. and Arokiyaraj, S. 2014. Bio-synthesis of NiO and $\mathrm{Ni}$ nanoparticles and their characterization. Dig. J. Nanomater. Bios., 9: 1007-1019.

Miessya, W., Yoki, Y., Iman, A., Dewangga, O. and Bagus, A. 2019. Synthesis of $\mathrm{NiO}$ nanoparticles via green route using Ageratum conyzoides L. leaf extract and their catalytic activity. IOP Conf. Series: Materials Science and Engineering, 509: 012- 077.

Morones, J.R., Elechiguerra, J.L. and Camacho, A. 2005. The bactericidal effect of silver nanoparticles. Nanotechnology, 16: 2346-2353.

Morton, J.F. 2016. The horseradish tree, Moringa pterygosperma (Moringaceae)-a boon to arid lands?. Economic Botany, 45(3): 318-333.

Motlagh, M., Kashani, M., Youzbashi, A. and Sabaghzadeh, L. 2011. Synthesis and characterization of nickel hydroxide/oxide nanoparticles by the complexation-precipitation method. Int. J. Phy. Sci., 6(6): $1471-1476$

Muhammad, A.R., Zakia, K., Anum, R., Anjum, N.S., Saira, R. and Shahzad, N. 2016. Size- and shape-dependent antibacterial studies of silver nanoparticles synthesized by wet chemical routes. Nanomaterials, 6: 74-76.

Rajesh, K., Ashwani, S., Nawal, K. and Narender, B. 2010. Preparation and characterization of $\mathrm{NiO}$ nanoparticles by co-precipitation method. Int. J. Eng. Appl. Manag. Sci. Paradig., 6(01): 2320-6608.

Raju, A. 2000. Wild Plants of Indian Sub-Continent and Their Economic Uses. CBS Pub. \& Distribution, New Delhi 65.

Sawai, J. and Microbiol, J. 2003. Quantitative evaluation of antibacterial activities of metallic oxide powders $(\mathrm{ZnO}, \mathrm{MgO}$ and $\mathrm{CaO})$ by conductimetric assay. Journal of Microbiological Methods, 54: 177-182.

Shanaj, B.R. and John, X.R. 2016. Effect of calcination time on structural, optical and antimicrobial properties of nickel oxide nanoparticles. J. Theor. Comput. Sci., 2(2): 1-10.

Srihasam, S., Thyagarajan, K., Korivi, M., Lebaka, V.R., and Mallem, S.P.R. 2020. Phytogenic Generation of NiO Nanoparticles Using Stevia Leaf Extract and Evaluation of Their In-Vitro Antioxidant and Antimicrobial Properties. Journal of Biomolecules, 10(1): 89.

Tortora, G., Funke, R.B. and Case, L.C. 2016. Microbiology: An Introduction. $12^{\text {th }}$ Edition, Addison Wesley. ISBN-13: 978-0321929150- ISBN10: 0321929152.

Wang, X., Yang, F., Yang, W. and Yang, X. 2007. A study on the antibacterial activity of one-dimensional $\mathrm{ZnO}$ nanowire arrays: Effects of the orientation and plane surface. Chem. Commun., 14: 4419-4421.

Wang, Y. 2009. Mutation in Rpa1 results in defective DNA double-strand break repair, chromosomal instability, and cancer in mice. Nat. Genet., 37(7): 750-755. 